УДК 338.1

Д. Д. Цыренов

Бурятский государственный университет, г. Улан-Удэ, Российская Федерация

\title{
ИНСТИТУЦИОНАЛИЗАЦИЯ ЭКОНОМИКИ ЗНАНИЙ
}

\begin{abstract}
АНнотАЦия. Основным критерием сформированности экономики знаний считается зрелость и устойчивость институциональной среды, включающей совокупность институтов развития и институтов управления, которые обеспечивают экономические отношения по поводу реализации функций знаний и модели поведения субъектов экономики знаний. Индексы знания и экономики знаний, рассчитываемые по методике Всемирного банка, характеризуют готовность страны к дальнейшему развитию. Согласно данному рейтингу для России характерна проблемная институциональная составляющая. В статье анализируются причины институциональных пробелов как для институтов развития, так и для институтов управления. Разработаны приоритетные направления государственной институциональной политики в области экономики знаний на федеральном уровне, а также отмечается необходимость дифференциации указанных направлений на региональном уровне. Предложен универсальный набор институциональных механизмов, который должен быть дополнен мерами, учитывающими уникальные региональные особенности.

кЛючЕВЫЕ СЛОВА. Знание; экономика знаний; Институционализация экономики знаний; институты развития; институты управления; институциональные пробелы. ИНФОРМАЦИЯ О СТАТЬЕ. Дата поступления 4 февраля 2016 г.; дата принятия к печати 25 февраля 2016 г.; дата онлайн-размещения 29 марта 2016 г.
\end{abstract}

D. D. Tsyrenov

Buryat State University,

Ulan-Ude, Russian Federation

\section{INSTITUTIONALIZATION OF THE KNOWLEDGE ECONOMY}

ABSTRACT. The main criterion of formedness the knowledge economy is the maturity and sustainability of the institutional environment, including an aggregate of institutions of development and institutions of administration which provide economic relations with regard to implementing the functions of knowledge and model of behavior of the knowledge economy subjects. The indices of knowledge and economy of knowledge calculated by the procedure of the World Bank characterize the country's willingness for further development. According to this rating, the problematic institutional component is characteristic of Russia. The article analyses the causes of institutional gaps both for institutions of development and institutions of knowledge. It develops the priority directions of national institutional policy in the field of knowledge economy at the federal level, as well as notes the necessity of differentiation of these directions at the regional level. It offers a universal set of institutional arrangements which should be supplemented with measures that take into account the unique regional features.

KEYWORDS. Knowledge; knowledge economy; Institutionalization of knowledge economy; institutions of development; institutions administration; institutional gaps.

ARTICLE INFO. Received February 4, 2016; accepted February 25, 2016; available online March 29, 2016.

Развитие экономики знаний объективно сопровождается его институционализацией [1]. Это предопределяет применение институционального подхода к анализу совокупности взаимосвязанных институтов, ролей, статусов, норм, ограничений, правил, контрактов, моделей поведения и принципов принятия решений.

(C) Д. Д. Цыренов, 2016

\section{Baikal Research Journal}


Экономика знаний возникла как ответ на необходимость использования накопленного человечеством критического объема знаний, стимулов и условий значительно возросшего спроса на новые технологии [2]. Институционализация, представляющая собой процесс определения и закрепления социальных норм, связей, статусов и ролей, а также приведения их в систему, состоит из следующих стадий:

- возникновение потребностей, которые можно удовлетворить только в результате совместной деятельности;

- появление норм и правил, регулирующих взаимодействие по удовлетворению возникших потребностей;

- принятие и реализация на практике появившихся норм и правил;

- создание системы статусов и ролей, охватывающих всех членов.

Институты служат уникальным эндогенным фактором становления экономики знаний, соотнесенным с определенным временем [3]. Некоторые структурные элементы экономики знаний исторически просматриваются на всей временной развертке [4]. С исторической точки зрения уклад всех обществ и цивилизаций в той или иной мере можно назвать знаниевым. На более ранних этапах развития человечества превалировала функция создания знания. Более поздние периоды характеризуются усложнениями функций знания [5].

Становление знания как главной движущей силы расширенного общественного воспроизводства произошло одновременно с существенным сокращением физического труда, массовой информатизацией и интеллектуализацией общественного уклада жизни [6]. Постиндустриальная экономика, характеризующаяся приматом сферы услуг [7], в результате повсеместного распространения вычислительной техники и информационных технологий с последующим формированием глобального информационного пространства посредством сети Интернет осуществила трансформационный сдвиг в сторону экономики, базирующейся на знании, к экономике знаний. Именно возможность передачи знания с минимальными трансакционными издержками транслировать их по всему доступному экономическому пространству послужило отправной точкой институционализации экономики знаний.

Единое информационное пространство в пределах глобализации позволяет с минимальными потерями передать огромный объем знания в любую точку земного шара. Вместе с тем протяженность маршрута трансляции знаний уже не является критически важным параметром. Материальный мир в информационной модели уже не зависит от его реальных размеров и позволяет осуществлять все функции знания с минимальными затратами. Благодаря этому сами знания институционализируются и выступают объектом купли-продажи на глобальном рынке.

Институциональные основы экономики знаний, по нашему мнению, представляют собой комплекс ключевых экономических, политических, правовых, финансовых, общественных структур, отношений и правил, которые регламентируют процессы воспроизводства, хранения, распространения и использования знания. Институциональная среда, определяющая экономику знаний, представляет собой взаимосвязанную совокупность институтов развития и институтов управления, обеспечивающих реализацию функций знания, формирующих модели поведения субъектов экономики знаний, определяющих нормы поведения и экономические отношения по поводу воспроизводства, хранения, распространения и использования знания [8].

Институциональная среда обеспечивает развертку экономики знаний через развитие инфраструктуры институтов развития и институтов управления (табл. 1).

\section{Baikal Research Journal}

электронный научный журнал Байкальского государственного университета 
Таблица 1

Инфраструктура институтов развития и институтов управления

\begin{tabular}{|c|c|c|}
\hline \begin{tabular}{c|} 
Формы \\
организации
\end{tabular} & $\begin{array}{c}\text { Инфраструктура } \\
\text { институтов }\end{array}$ & Характеристика \\
\hline \multirow[t]{4}{*}{$\begin{array}{l}\text { Институты } \\
\text { развития }\end{array}$} & Воспроизводства & $\begin{array}{l}\text { Академия наук РФ, центры исследований и разработок, опыт- } \\
\text { но-конструкторские организации, проектные бюро }\end{array}$ \\
\hline & Хранения & $\begin{array}{l}\text { Сеть архивов, федеральная, региональные и муниципальные } \\
\text { библиотечные системы }\end{array}$ \\
\hline & $\begin{array}{l}\text { Распростране- } \\
\text { ния }\end{array}$ & $\begin{array}{l}\text { Образовательные комплексы, учреждения начального, сред- } \\
\text { него и высшего профессионального образования, дополнитель- } \\
\text { ного и послевузовского образования, центры корпоративного } \\
\text { обучения }\end{array}$ \\
\hline & Использования & $\begin{array}{l}\text { Бизнес-инкубаторы, технопарки, центры трансфера техноло- } \\
\text { гий, инновационные предприятия }\end{array}$ \\
\hline \multirow[t]{4}{*}{$\begin{array}{l}\text { Институты } \\
\text { управления }\end{array}$} & Правовые & $\begin{array}{l}\text { Защита прав интеллектуальной собственности, патентная } \\
\text { система, система лицензирования }\end{array}$ \\
\hline & Политические & Конкурентная среда, общественный порядок \\
\hline & Финансовые & $\begin{array}{l}\text { Банки, страховые компании, венчурные фонды, гарантийные } \\
\text { фонды }\end{array}$ \\
\hline & Общественные & $\begin{array}{l}\text { Склонность к рационализаторству, средства массовой инфор- } \\
\text { мации, объединения инноваторов, свобода мысли, самосто- } \\
\text { ятельность и независимость творческих, научных и других } \\
\text { объединений }\end{array}$ \\
\hline
\end{tabular}

Математически перечисленные объекты инфраструктуры институциональной среды экономики знаний нашли свое отражение в индексах знания и экономики знаний, предложенных в 2004 г. Всемирным банком [9]. Первый определяется как средняя величина от трех индексов (образование; инновации; информационные технологии и коммуникации). Второй показатель представляет собой среднее значение четырех индексов (институциональный режим экономики; образование; инновации; информационные технологии и коммуникации) (рис.).

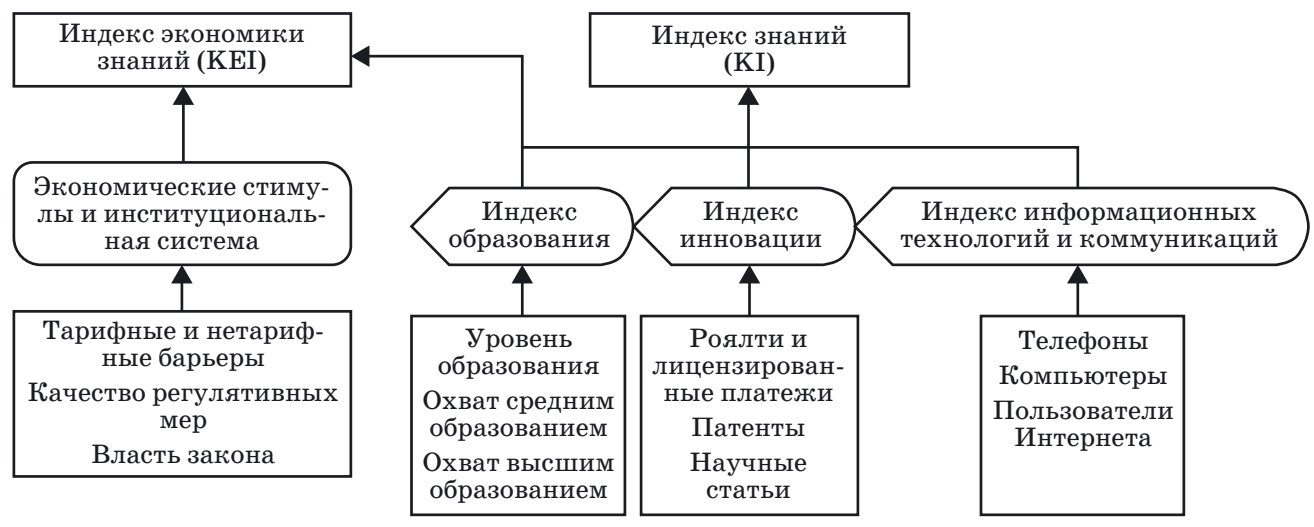

Индексы знаний и эконолики знаний

Указанные индексы используются для оценки готовности страны к дальнейшему развитию экономики знаний и выявления проблемных мест в их политике [10]. По каждой группе показателей странам выставляется оценка в баллах от 1 до 10. Чем выше бал, тем более высокую позицию занимает государство по данному критерию (табл. 2).

\section{Baikal Research Journal}


Таблица 2

Индекс эконолики знаний и его составляющие за 2004, 2009 и 2012 г2.

\begin{tabular}{|c|c|c|c|c|c|c|}
\hline Год & Страна & $\begin{array}{c}\text { Индекс } \\
\text { экономики } \\
\text { знаний }\end{array}$ & $\begin{array}{c}\text { Институцио- } \\
\text { нальный режим } \\
\text { экономики }\end{array}$ & Инновации & Образование & $\begin{array}{c}\text { Информационные } \\
\text { технологии и ком- } \\
\text { муникации }\end{array}$ \\
\hline \multirow[t]{10}{*}{2004} & Швеция & 9,25 & 8,36 & 9,67 & 9,20 & 9,78 \\
\hline & США & 8,69 & 7,81 & 9,47 & 8,43 & 9,03 \\
\hline & Германия & 8,38 & 7,95 & 8,88 & 7,87 & 8,82 \\
\hline & Тайвань & 7,98 & 7,10 & 8,86 & 6,98 & 8,96 \\
\hline & Корея & 7,70 & 6,10 & 7,88 & 7,80 & 9,03 \\
\hline & Чехия & 6,80 & 6,10 & 6,76 & 7,07 & 7,28 \\
\hline & Россия & 5,69 & 2,43 & 7,57 & 7,52 & 5,25 \\
\hline & Бразилия & 5,03 & 3,92 & 4,84 & 5,55 & 5,82 \\
\hline & Мексика & 5,01 & 5,55 & 4,64 & 4,61 & 5,24 \\
\hline & Китай & 3,50 & 2,42 & 4,18 & 3,04 & 4,35 \\
\hline \multirow[t]{10}{*}{2009} & Швеция & 9,51 & 9,33 & 9,76 & 9,29 & 9,66 \\
\hline & США & 9,02 & 9,04 & 9,47 & 8,74 & 8,83 \\
\hline & Германия & 8,96 & 9,06 & 8,94 & 8,36 & 9,47 \\
\hline & Тайвань & 8,45 & 7,42 & 9,27 & 7,91 & 9,13 \\
\hline & Корея & 7,82 & 6,00 & 8,60 & 8,09 & 8,60 \\
\hline & Чехия & 7,97 & 8,17 & 7,78 & 8,23 & 7,70 \\
\hline & Россия & 5,50 & 1,76 & 6,88 & 7,19 & 6,38 \\
\hline & Бразилия & 5,66 & 4,31 & 6,19 & 6,02 & 6,13 \\
\hline & Мексика & 5,33 & 5,06 & 5,82 & 4,88 & 5,56 \\
\hline & Китай & 4,47 & 3,90 & 5,44 & 4,20 & 4,33 \\
\hline \multirow[t]{10}{*}{2012} & Швеция & 9,43 & 9,58 & 9,74 & 8,92 & 9,49 \\
\hline & США & 8,77 & 8,41 & 9,46 & 8,70 & 8,51 \\
\hline & Германия & 8,90 & 9,10 & 9,11 & 8,20 & 9,17 \\
\hline & Тайвань & 8,77 & 7,77 & 9,38 & 8,87 & 9,06 \\
\hline & Эстония & 8,40 & 8,81 & 7,75 & 8,60 & 8,44 \\
\hline & Чехия & 8,14 & 8,53 & 7,90 & 8,15 & 7,96 \\
\hline & Россия & 5,78 & 2,23 & 6,93 & 6,79 & 7,16 \\
\hline & Бразилия & 5,58 & 4,17 & 6,31 & 5,61 & 6,24 \\
\hline & Мексика & 5,07 & 4,88 & 5,59 & 5,16 & 4,65 \\
\hline & Китай & 4,37 & 3,79 & 5,99 & 3,93 & 3,79 \\
\hline
\end{tabular}

Представленная статистическая информация позволяет увидеть, что средняя величина индекса экономики знаний находится в пределах от 5 до 6 . Первая тройка государств в этом рейтинге не изменяется: Швеция, США и Германия. Россия согласно данному рейтингу имеет следующие значения: 2004 г. — 5,69; 2009 г. 5,50; 2012 г. - 5,78. Стабильный рост демонстрирует показатель информационной инфраструктуры, что связано с повсеместной компьютеризацией в России, широким охватом информационными технологиями и повышением компьютерной грамотности. Однако негативная тенденция присутствует при вычислении индекса образования: 6,79 в 2012 г. против 7,52 в 2004 г. Относительно стабилен индекс инноваций (7,57 - 2004 г.; 6,88 - 2009 г.; 6,93 - 2012 г.). Наихудшие показатели наблюдаются при расчете индекса институционального режима экономики: $2,43-$ 2004 г.; 1,76 - 2009 г.; 2,23 - 2012 г.

Индекс экономики знаний, рассчитываемый по многим показателям по всем странам, обнажил комплекс проблем, связанных со сменой общественно-политиче-

\section{Baikal Research Journal}


ских формаций в России, который и предопределил низкое место в рейтинге стран [11]. С начала реализации реформ, направленных на формирование либерально-рыночных отношений, и примененной «шоковой терапии» произошел разрыв между академическим и прикладным секторами народного хозяйства. Научно-образовательный комплекс функционировал в условиях постоянно снижающегося финансирования со стороны государства и частного сектора, что неминуемо привело к падению роли и статуса научного сотрудника и педагога [12].

Рост мировых цен на углеводороды с конца XX столетия позволил увеличить инвестиционные настроения корпоративного сектора экономики, а рост реальных доходов населения привел к ускоренному росту обеспеченности домашних хозяйств персональными компьютерами с доступом в глобальную сеть. На государственном уровне в этот период времени были разработаны и приняты различные федеральные целевые программы, определившие приоритет образования и науки, например: федеральная целевая программа «Электронная Россия» (2002-2010), Стратегия развития науки, технологий и техники в РФ (2006), приоритетный национальный проект «Образование» (2005), Стратегия инновационного развития РФ на период до 2020 года (2008).

В этот период публичное обсуждение прошли следующие документы: Перечень критических технологий РФ (2002 и 2006 г.), федеральный закон «Об образовании» (2012). Особым статусом наделены вновь созданные институты содействия развитию экономики знаний: Российская венчурная компания (2006), Российская корпорация нанотехнологий (2007), инновационный центр «Сколково» (2010). Понимание важности образования в дальнейшей развертке экономики знаний Правительством РФ привело к формированию вузов-лидеров, к числу которых на сегодняшний день относятся 10 федеральных университетов (Балтийский, Дальневосточный, Казанский, Крымский, Северный (Арктический), Северо-Восточный, Северо-Кавказский, Сибирский, Южный и Уральский), 29 научно-исследовательских университетов и 2 университета с особым автономным статусом (Московский государственный университет и Санкт-Петербургский государственный университет).

Вместе с тем, место России в мировом рейтинге по уровню экономики знаний демонстрирует, что наиболее проблемной характеристикой выступает именно институциональная составляющая [13]. Наиболее значимые институциональные пробелы в экономике знаний в современных условиях представлены в табл. 3 .

Формирование институциональной структуры и инфраструктуры нового технологического уклада, являющегося базисом становления и развития экономики знаний, требует от государства проведения системной и гибкой институциональной политики мягкого принуждения. Реализация такой государственной политики зависит от уровня управления (федерального и регионального) и имеет различные механизмы их внедрения [14].

На федеральном уровне нам видятся следующие приоритетные направления государственной институциональной политики в области экономики знаний:

- изменение бюджетных приоритетов в сторону увеличения объемов финансирования науки из средств федерального бюджета РФ (при 0,51 \% в 2015 г. до 3 \% к 2020 г.);

- поэтапное повышение финансирования инициативных проектов Российского фонда фундаментальных исследований, Российского гуманитарного научного фонда и Российского научного фонда типа «а» и последующее сокращение отрыва от аналогичных зарубежных грантовых фондов;

- отход от централизованного определения приоритетов научно-технологического развития страны;

- расширение сферы применения и дальнейшее совершенствование механизма конкурсного финансирования научных исследований на основе независимой, прозрачной и качественной экспертизы;

\section{Baikal Research Journal}




\section{Институциональные пробель}

\begin{tabular}{|l|l|}
\hline $\begin{array}{l}\text { Институты развития } \\
\text { и управления }\end{array}$ & \multicolumn{1}{|c|}{ Институциональные пробелы } \\
\hline $\begin{array}{l}\text { Институты воспроиз- } \\
\text { водста }\end{array}$ & $\begin{array}{l}\text { Отставание от ведущих стран мира по объемам государственной и част- } \\
\text { ной грантовой поддержки научно-исследовательской деятельности }\end{array}$ \\
\hline $\begin{array}{l}\text { Языковые барьеры в последующая неразвитость совместных межгосу- } \\
\text { дарственных изыскательских проектов }\end{array}$ \\
\hline Институты хранения & $\begin{array}{l}\text { Асимметрия и неполнота информации субъектов научной и инвестици- } \\
\text { онной сферы }\end{array}$ \\
\hline $\begin{array}{l}\text { Низкий уровень грамотности в области защиты интеллектуальной соб- } \\
\text { ственности }\end{array}$ \\
\hline $\begin{array}{l}\text { Институты распро- } \\
\text { странения }\end{array}$ & $\begin{array}{l}\text { Непрестижность естественно-научных направлений образовательных } \\
\text { программ профессионального образования }\end{array}$ \\
& $\begin{array}{l}\text { Деформация структуры рабочего времени профессорско-преподаватель- } \\
\text { ского состава учебных заведений }\end{array}$ \\
\hline $\begin{array}{l}\text { Институты использо- } \\
\text { вания }\end{array}$ & $\begin{array}{l}\text { Дефицит институтов венчурного инвестирования } \\
\text { нияий уровень грамотности в области бизнес-планирования и управле- }\end{array}$ \\
\hline Правовые институты & Нечеткость терминологии \\
\hline $\begin{array}{l}\text { Политические ин- } \\
\text { ституты }\end{array}$ & $\begin{array}{l}\text { Превалирование «технократической» идеологии в приоритетных на- } \\
\text { правлениях развития науки, технологий и техники }\end{array}$ \\
\hline $\begin{array}{l}\text { Финансовые инсти- } \\
\text { туты }\end{array}$ & Постоянная смена механизмов финансирования экономики знаний \\
\hline $\begin{array}{l}\text { Общественные ин- } \\
\text { ституты }\end{array}$ & Массовое изменение сознания в сторону общества потребления \\
\hline
\end{tabular}

- преодоление дискриминационного отношения к общественным и гуманитарным наукам, которые по своей сути являются проводниками и адапторами новых технологических укладов и минимизируют транзакционные издержки;

- дальнейшее совершенствование системы образования под потребности рынка труда;

- внедрение системы эффективных контрактов для оплаты труда работников умственного труда;

- активизация выделения грантовой поддержки научным творческим коллективам под руководством молодых ученых и исследователей;

- выработка единых критериев идентификации «знаниевых» хозяйствующих субъектов с целью дальнейшей их поддержки с помощью финансовых инструментов (льготные кредиты, налоговые каникулы и т. д.);

- развитие методики статистического учета деятельности хозяйствующих субъектов, функционирующих в экономике знаний;

- разработка мер мягкого принуждения хозяйствующих субъектов к внедрению результатов экономики знаний;

- создание и внедрение государственной программы стимулирования совокупного спроса (со стороны населения, государства и хозяйствующих субъектов) на отечественную продукцию, произведенную в экономике знаний;

- стимулирование хозяйствующих субъектов к экспорту технологий экономики знаний, имеющих соответствующую охрану интеллектуальной собственности, и товаров (услуг), произведенных экономикой знаний;

- дальнейшая повсеместная ликвидация безграмотности в области защиты интеллектуальной собственности и применения механизмов частно-государственного партнерства;

\section{Baikal Research Journal}


- повышение эффективности институциональных механизмов закрепления и передачи прав интеллектуальной собственности.

На региональном уровне развертка экономики знаний должна осуществляться с учетом особенностей и существенной пространственной дифференциацией регионов по стартовому уровню формирования экономики знаний [15]. Предлагаем универсальный набор институциональных механизмов, рекомендуемых для внедрения во всех регионах вне зависимости от существующей специализации народного хозяйства региона, его отраслевой структуры и других особенностей:

- стимулирование научных разработок через механизмы премирования лучших научно-исследовательских практик;

- расширение использования технологий коворкинга и краудсорсинга;

- широкое привлечение научной общественности к разработке и экспертизе стратегических документов регионального уровня;

- создание и поддержка научно-образовательно-внедренческих корпораций полного цикла инноваций;

- ведение реестра хозяйствующих субъектов экономики знаний с дальнейшей поддержкой на конкурсной основе проектов, способных формировать ядро точек роста региональной экономики;

- активизация деятельности региональных органов государственной власти и органов местного самоуправления к дальнейшей развертке кластерной политики;

- гармонизация интересов общества, бизнеса и государства через механизмы создания объектов инфраструктуры коммерциализации (бизнес-инкубаторы, технопарки и т. д.);

- формирование уникального бренда каждого региона для определения его места в федеральном пространстве экономики знаний;

- реализация программ поддержки субъектов малого и среднего предпринимательства, функционирующих в экономике знаний.

Реализация комплекса предложенных мер по совершенствованию институциональной среды экономики знаний должна осуществляться вместе с повышением качества индикаторов экономики знаний [16]. Неприемлемым является рост количества создаваемых инфраструктурных объектов без соответствующего качества выполняемых ими функций. Так, созданные по всей стране в 2000-х гг. технопарки фактически выполняли функции офисных центров.

Таким образом, первоначально институционализация экономики знаний проявилась в определении и закреплении норм, связей, статусов и ролей, а также приведении их в систему экономики знаний. Последующее развитие экономики знаний в России связано с совершенствованием институциональной среды и перестройкой имеющихся инфраструктурных объектов под нужды знаниевой экономики.

\section{Список использованной литературы}

1. Рябова Е. Ю. Институциональные императивы функционирования экономики знаний / Е. Ю. Рябова // Terra Economicus. - 2009. - Т. 7, № 2-3. - C. 27-31.

2. Цыренов Д. Д. Экономическая сущность и природа знания в экономике знаний / Д. Д. Цыренов // Вестник Белгородского университета кооперации, экономики и права. 2014. — № 2 (50). - С. 389-397.

3. Малышев Е. А. Институциональная роль высшей школы и науки в региональном саморазвитии / Е. А. Малышев // Образование. Наука. Научные кадры. - 2012. — № 5. — С. 97-101.

4. Пенькова И. В. Экономика знаний: институциональные трансформации / И. В. Пенькова // Экономика промышленности. - 2009. - Т. 44, № 1. - С. 13-21.

5. Шелестова Д. А. Сущность и институциональная специфика «экономики знаний»/ Д. А. Шелестова // Современная экономика: проблемы и решения. - 2011. — № 12 (24). C. $22-36$.

\section{Baikal Research Journal}


6. Мункуева И. С. Знания как наиболее производительный ресурс инновационной экономики / И. С. Мункуева / Вестник Бурятского государственного университета. - 2014. № 2. - С. 26-28.

7. Рубан В. А. Проблемы развития социальной инфраструктуры региона / В. А. Рубан // Российское предпринимательство. - 2012. - № 9. - С. 148-151.

8. Цыплакова Д. А. Вся наша жизнь... среда. Институциональная среда как детерминирующий фактор формирования экономики знаний в России / Д. А. Цыплакова // Креативная экономика. - 2010. - № 4. - С. 98-105.

9. Цыренов Д. Д. Рейтинг регионов в зависимости от уровня развития экономики знаний / Д. Д. Цыренов, Л. Р. Слепнева // Известия Санкт-Петербургского государственного экономического университета. - 2015. - № 2 (92). - С. 24-28.

10. Кузьмина О. Ю. Институциональное регулирование процессов формирования и функционирования интеллектуального капитала / О. Ю. Кузьмина / Известия Оренбургского государственного аграрного университета. — 2015. — № 2 (52). — С. 202-204.

11. Попов Е. В. Институциональное проектирование генерации знаний / Е. В. Попов, М. В. Власов, А. Ю. Веретенникова // Вестник Уральского федерального университета. Сер. Экономика и управление. - 2011. - № 5. - С. 4-16.

12. Веретенникова А. Ю. Развитие региональной институциональной системы генерации знаний / А. Ю. Веретенникова // Шумпетеровские чтения : материалы 3-й Междунар. науч.-практ. конф. - Пермь : Изд-во Перм. нац. исслед. политехн. ун-та. — 2013. Вып. 1. - С. 122-124.

13. Попов Е. В. Институты регионального развития экономики знаний / Е. В. Попов, М. В. Власов, М. О. Симахина // Региональная экономика: теория и практика. - 2010. № 4. - C. 2-7.

14. Атанов Н. И. Повышение качества работы региональных институтов государственного управления в Сибирском федеральном округе / Н. И. Атанов, А. Е. Янтранов // Вестник Забайкальского государственного университета. — 2015. — № 9 (124). — С. 88-94.

15. Дондокова Е. Б. Интеллектуальные ресурсы как элемент обеспечения развития региональных инновационных систем / Е. Б. Дондокова, Ю. В. Слепнева // Вестник Восточно-Сибирского государственного университета технологий и управления. - 2013. — № 3 (42). С. $73-79$.

16. Власов М. В. К вопросу о классификации миниэкономических институтов производства новых знаний / М. В. Власов, Е. В. Попов // Вестник Уральского федерального университета. Сер. Экономика и управление. - 2007. — № 1. - С. 4-10.

\section{References}

1. Ryabova E. Yu. Institutional imperatives of functioning of knowledge economy. Terra Economicus, 2009, vol. 7, no. 2-3, pp. 27-31. (In Russian).

2. Tsyrenov D. D. Economic essence and nature of knowledge in the knowledge economy. Vestnik Belgorodskogo universiteta kooperatsii, ekonomiki i prava=Bulletin of Belgorod University of Cooperation, Economics and Law, 2014, no. 2 (50), pp. 389-397. (In Russian).

3. Malyshev E. A. Institutional role of the higher school and science in regional self-development. Obrazovanie. Nauka. Nauchnye kadry = Science. Education. Academic staff, 2012, no. 5, pp. 97-101. (In Russian).

4. Penkova I. V. Knowledge economy: institutional transformations. Ekonomika promyshlennosti $=$ Industrial Economy, 2009, vol. 44, no. 1, pp. 13-21. (In Russian).

5. Shelestova D. A. Essence and institutional specificity of «knowledge economy». Sovremennaya ekonomika: problemy i resheniya = Modern Economics: Problems and Solutions, 2011, no. 12 (24), pp. 22-36. (In Russian).

6. Munkuyeva I. S. Knowledge as the most productive resource of innovative economy. Vestnik Buryatskogo gosudarstvennogo universiteta $=$ Bulletin of Buryat State University, 2014, no. 2, pp. 26-28. (In Russian).

7. Ruban V. A. Problems of developing regional social infrastructures. Rossiiskoe predprinimatel'stvo = Russian Entrepreneurship, 2012, no. 9, pp. 148-151. (In Russian).

8. Tsyplakova D. A. All our life is... but an environment. Institutional environment as a determining factor of developing knowledge economy in Russia. Kreativnaya ekonomika $=$ Creative Economy, 2010, no. 4, pp. 98-105. (In Russian).

\section{Baikal Research Journal}


9. Tsyrenov D. D., Slepneva L. R. Rating of regions depending on level of knowledge economy development. Izvestiya Sankt-Peterburgskogo gosudarstvennogo ekonomicheskogo universiteta = Bulletin of Saint Petersburg State University of Economics, 2015, no. 2 (92), pp. 24-28. (In Russian).

10. Kuzmina O. Yu. Institutional regulation of processes of developing and functioning of intellectual capita. Izvestiya Orenburgskogo gosudarstvennogo agrarnogo universiteta = Bulletin of Orenburg State Agrarian University, 2015, no. 2 (52), pp. 202-204. (In Russian).

11. Popov E. V., Vlasov M. V., Veretennikova A. Yu. Institutional designing of knowledge generation by business entities. Vestnik Ural'skogo federal'nogo universiteta. Seriya: Ekonomika $i$ upravlenie = Bulletin of Ural Federal University. Series Economics and Management, 2011, no. 5, pp. 4-16. (In Russian).

12. Veretennikova A. Yu. Regional institutional development of knowledge generation. Shumpeterovskie chteniya. Materialy 3-i Mezhdunarodnoi nauchno-prakticheskoi konferentsii [Schumpeterian Readings. Materials of the 3-rd International Research Conference]. Perm National Research Polytechnic University Publ., 2013, iss 3, pp. 122-124. (In Russian).

13. Popov E. V., Vlasov M. V., Simakhina M. O. Institutions of regional development of knowledge economy. Regional'naya ekonomika: teoriya i praktika = Regional Economy: Theory and Practice, 2010, no. 4, pp. 2-7. (In Russian).

14. Atanov N. I., Yantranov A. E. Improving quality of regional institutions of public administration in the Siberian Federal District. Vestnik Zabaikal'skogo gosudarstvennogo universite$t a=$ Bulletin of Zabaikalsky State University, 2015, no. 9 (124), pp. 88-94. (In Russian).

15. Dondokova E. B., Slepneva Yu. V. Intellectual resources as an element of providing development of regional innovative systems. Vestnik Vostochno-Sibirskogo gosudarstvennogo universiteta tekhnologii $i$ upravleniya = East-Siberian State University of Technology and Management Bulletin, 2013, no. 3 (42), pp. 73-79. (In Russian).

16. Vlasov M. V., Popov E. V. On issue of classification of mini-economic institutions of new knowledge production. Vestnik Ural'skogo federal'nogo universiteta. Seriya: Ekonomika i upravlenie = Bulletin of Ural Federal University. Series Economics and Management, 2007, no. 1, pp. 4-10. (In Russian).

\section{Информация об авторе}

Даши Цыренов Дашанимаевич - кандидат экономических наук, доцент, заведующий кафедрой эконометрики и прикладной экономики, Бурятский государственный университет, 670000, г. Улан-Удэ, ул. Смолина, 24a, e-mail: dashi555@mail.ru.

\section{Author}

Dashi D. Tsyrenov - PhD in Economics, Assistant Professor, Head of Chair of Econometrics and Applied Economics, Buryat State University, 24a Smolin St., 670000, Ulan-Ude, Russian Federation; e-mail: dashi555@mail.ru.

\section{Библиографическое описание статьи}

Цыренов Д. Д. Институционализация экономики знаний / Д. Д. Цыренов // Baikal Research Journal. - 2016. — T. 7, № 2. — DOI : 10.17150/2411-6262.2016.7(2).2.

\section{Reference to article}

Tsyrenov D. D. Institutionalization of the knowledge economy. Baikal Research Journal, 2016, vol. 7, no. 2. DOI: 10.17150/2411-6262.2016.7(2).2. (In Russian).

\section{Baikal Research Journal}

